\title{
Literatura e direitos humanos na obra de Sacolinha
}

Leila Lehnen $^{1}$

A nota introdutória a alguns dos livros publicados na coleção Tramas Urbanas, patrocinada pela Petrobras e coordenada por Heloísa Buarque de Holanda, afirma que "mais que a internet, a periferia é a grande novidade do século XXI". Essa novidade e a atenção crítica dada a ela reflete de certo modo as mudanças sociais ocorridas no Brasil na última década. Além da transição democrática em 1985 e a promulgação de uma nova Constituição em 1988, pode-se citar a redução da pobreza através de programas sociais, tais como o Bolsa Família, decisivos no grande aumento da chamada classe C ou classe média emergente. ${ }^{2}$ Essa "nova" classe social não somente introduziu um grande número de novos consumidores no mercado brasileiro; seus integrantes cada vez mais reclamam e procuram uma visibilidade sociocultural. Manifestações disso são, por exemplo, em anos recentes, os rolezinhos, a dança do passinho, a popularidade dos bailes funk e até mesmo o protagonismo dos integrantes dessa classe em novelas, como, por exemplo, no caso da TV Globo, Avenida Brasil (João Emanuel Carneiro, 2012), Salve Jorge (Glória Pérez, 2012), Cheias de Charme (Felipe Miguez et al., 2012) e Babilônia (Gilberto Braga et al., 2015). Todas essas manifestações atestam um crescimento da presença social, do poder de consumo e da consciência dos direitos da classe emergente. Assim sendo, as expressões sociais e culturais da classe $\mathrm{C}$ ganharam visibilidade midiática e, até certo ponto, também legitimidade. ${ }^{3}$

De certa forma a ascensão econômica e sociocultural da classe C também contribuiu para a difusão e o crescimento da literatura periférica - textos literários sobre os espaços urbanos periféricos e

\footnotetext{
${ }^{1}$ Doutora em literatura espanhola e brasileira e professora de literatura e cultura brasileira e hispano americana da University of New Mexico, Albuquerque, Estados Unidos. E-mail: 1lehnen@unm.edu

${ }^{2}$ Este ensaio não discute os méritos e a problemática dessa classificação. Tendo em conta as recentes transformações socioeconômicas no Brasil, tal como a redução, conforme o Instituto de Pesquisa Econômica Aplicada (Ipea, 2013, p. 18), da taxa de pobreza entre 1992 e 2012, de 31,5\% para 8,5\%, o que representa 28 milhões a menos de pessoas vivendo na linha de pobreza, considera-se consolidada a significância dessa camada social.

${ }^{3}$ A legitimidade sociocultural outorgada pela visibilidade midiática se expressa, por exemplo, no programa Central da periferia, criado pela atriz Regina Casé, que ia ao ar aos sábados de 8 de abril a 23 de dezembro de 2006, na Rede Globo.
} 
produzida por autores da periferia. ${ }^{4}$ Para Fernando Villarraga Eslava, há uma "invasão" da república letrada brasileira por escritores advindos das margens sociais (Eslava, 2004, p. 35). Já Regina Dalcastagnè associa a produção literária de grupos marginalizados com a "necessidade de democratização no processo de produção da literatura - que jamais estará desvinculada da necessidade de democratização do universo social" (Dalcastagnè, 2008, p. 102). Embora a hipótese de Eslava pareça substanciar-se na publicação da obra de certos autores periféricos por grandes casas editoriais, tanto nacionais como internacionais, tais como Companhia das Letras, Objetiva e Planeta, a maior parte dos autores periféricos ainda luta para ter seus textos publicados e reconhecidos por seu valor literário e não somente pelo aspecto "testemunhal" e/ou sociológico. Ou seja, a democratização do campo literário brasileiro ainda é um processo incompleto, refletindo de certa forma as lacunas do sistema democrático na esfera política, civil e social.

Posicionada entre o imperativo da democratização literária/cultural e a democratização social e cívica, a literatura periférica é parte de um vasto repertório cultural da periferia que inclui fenômenos tais como o rap e as performances literárias dos saraus. Como o rap e os saraus, a literatura periférica (me refiro aqui a textos publicados, que, no entanto, muitas vezes também fazem parte do circuito oral dos saraus), tematicamente se concentra na realidade da periferia. Referindo-se aos saraus da periferia de São Paulo, a pesquisadora argentina Lucía Tennina afirma que: “É comum nos textos declamados pelos moradores nos saraus que se fale sobre a realidade sem focar a ação, isto é, sem espetacularizar a pobreza, mas concentrando-se em experiências do dia a dia e nos detalhes ínfimos que conformam a vida nas regiões pobres da cidade" (Tennina, 2013, p. 16). Como nos saraus, a atenção ao dia a dia da periferia urbana dentro da literatura periférica escrita tem três objetivos. Por um lado,

\footnotetext{
${ }^{4}$ Neste ensaio, optei por usar o termo "periférica", em vez de "marginal", por dois motivos. Primeiro, o termo marginal evoca o movimento literário da década de 1970, composto majoritariamente por membros da classe média. Segundo, porque "marginal" também evoca uma ideia de criminalidade que muitos textos da literatura produzida por autores/as advindos/as das periferias urbanas brasileiras (suas "margens" por assim dizer) tentam refutar ou pelo menos problematizar. No entanto, há em geral certa fluidez no uso da classificação de literatura marginal e/ou literatura periférica. É claro que o termo "literatura periférica" também implica certa problemática, como a associação entre uma produção literária e um determinado espaço físico.
} 
desconstrói o mito desse território como um espaço de marginalidade, crime, violência e falta de sociabilidade, ao pintar os detalhes muitas vezes corriqueiros da vida dos seus moradores (a rotina do fim de semana, os espaços domésticos, as brincadeiras infantis etc.). Nessa representação, a periferia se revela como um terreno de múltiplas formas de sociabilidade. Por outro lado, o enfoque no cotidiano dentro da literatura periférica também revela as dificuldades enfrentadas por amplos segmentos da população brasileira em função de condições socioeconômicas adversas. Textos periféricos muitas vezes retratam espaços públicos negligenciados e infraestrutura deficiente. E, com frequência, aparecem também violações de direitos da cidadania, como violência policial, preconceito etc.

Para Julia Eckert, a violação da lei - nesse caso, especificamente dos direitos articulados pela Constituição brasileira - pode dar início à luta pelos direitos que foram violados. Eckert afirma que a "lei é importante mesmo quando é violada por aqueles que detêm o poder, pois é a base a partir da qual se pode identificar a violação e sua alternativa" (Eckert, 2011, p. 315, tradução nossa). Assim, combinando os dois objetivos supracitados - a normalização e a denúncia -, o terceiro alvo da literatura periférica é enunciar os direitos humanos ${ }^{5}$ dos moradores das periferias urbanas e, através dessa articulação, sua inserção dentro da polis -6 entendida aqui não apenas como um espaço físico mas também um território político, social e simbólico.

A reivindicação dos direitos se dá, justamente, por meio da junção entre a exposição da cotidianidade da vida na periferia urbana, a "normalização" desse espaço geosimbólico e de seus residentes e a revelação dos problemas enfrentados pela população das periferias.

No entanto, a literatura periférica não pode ser reduzida apenas a um instrumento de denúncia social. Como indica Tennina em relação aos saraus da periferia, estes ressignificam a ideia de "periferia" "como modo de vida... Quase todos os poemas declamados têm a ver com a conformação de uma geografia afetiva, a partir de uma atenção voltada para as vivências apreendidas no dia a dia da comunidade, traçando uma estética particular nessas reconfigurações" (Tennina,

\footnotetext{
${ }^{5}$ Neste ensaio, "direitos humanos" se refere a direitos sociais, culturais, políticos, econômicos, sociais e civis.

${ }^{6} \mathrm{O}$ termo polis é usado aqui como sinônimo da ideia de cidadania, de pertencimento a um estado e dos direitos e deveres que isso implica tanto por parte do Estado quanto do cidadão.
} 
2013, p. 16). Por sua vez, para Rejane Pivetta, a literatura periférica assume um caráter testemunhal coletivo que, ao mesmo tempo que se opõe a uma cultura hegemônica, também se insere dentro desta, ao usar muitos de seus canais de divulgação cultural (Pivetta, 2011, p. 34). Ou seja, a literatura periférica, seja ela declamada ou escrita, se apropria da ideia de periferia como um marco de identificação positiva. Dessa forma, esse tipo de produção literária desconstrói a negatividade que a sociedade hegemônica atribui a sujeitos, espaços e expressões culturais provenientes da periferia.

Finalmente, pode-se dizer que a literatura periférica profere os anseios de um segmento social que está posicionado entre as aspirações de ascensão social da classe média emergente e as condições materiais e culturais que dificultam - quando não impedem - essa mobilidade. Ao retratar essa tensão, a literatura periférica se afirma como instrumento de denúncia e como meio de mobilidade/mobilização sociocultural.

Este artigo propõe examinar como textos de escritores da periferia urbana brasileira - especificamente a obra de Ademiro Alves, o Sacolinha - reivindicam os direitos humanos dos residentes da periferia, portanto, de sua inclusão na polis, através do nexo entre a representação da cotidianidade e da injustiça social na periferia urbana brasileira. Serão analisadas duas obras de Sacolinha: seu romance Graduado em marginalidade (2005) e sua biografia Como a água do rio (2013). Por meio da representação da injustiça social (agressão policial, desigualdade socioeconômica, entre outros) e do retrato da cotidianidade na periferia, que ocorrem de forma paralela nos textos aqui examinados, Sacolinha tanto aponta as condições socioeconômicas adversas em que vivem muitos residentes das periferias brasileiras, como valoriza a comunidade e a cultura da periferia. Seus textos sugerem, por um lado, que os moradores das periferias brasileiras são vítimas de violações de direitos humanos e, por outro, que têm direito a ter direitos (Arendt, 1951/1966).

O discurso dos direitos humanos na literatura periférica brasileira revela a dialética entre denúncia e afirmação sociocultural que permeia os textos de autores da periferia. Essa dialética entre denúncia e validação que caracteriza a produção literária da periferia demonstra a transformação socioeconômica no Brasil em anos recentes, com o empoderamento material e simbólico de certos setores populacionais, ao mesmo tempo que mostra a continuidade de mecanismos de exclusão social e simbólica, resultado do que o 
pesquisador norte-americano James Holston denomina de democracia disjuntiva (Holston, 2007).

Para Holston, uma das características da democracia disjuntiva é uma cidadania formalmente inclusiva, mas desigual na práxis, que perpetua a histórica "gradação dos direitos" (Holston, 2008, p. 7, tradução nossa). Holston concentra-se, principalmente, na diferenciação dos direitos civis presente no código legal e na sociedade brasileira. A obra de Sacolinha mostra esses dois lados negativos da democracia disjuntiva - o diferencial tanto no âmbito dos direitos civis como no dos direitos sociais, demonstrando que "enquanto a redemocratização outorgou aos pobres dos centros urbanos uma cidadania de jure, estes não sentem que possuem uma cidadania de facto. Eles são pseudocidadãos" (Perlman, 2008, p. 262, tradução nossa).

No entanto, os textos de Sacolinha também revelam a progressão da democracia brasileira no sentido de inclusão de muitos de seus membros tradicionalmente desprivilegiados. Tomando-se essas premissas em consideração, sugere-se, por um lado, que as duas obras de Sacolinha representam a democratização - ainda que parcial e incompleta - da literatura brasileira contemporânea, tanto em termos de quem a produz (setores tradicionalmente marginalizados) como em termos do desenvolvimento temático. Os livros de Sacolinha refletem, como a implementação de novos regimes democráticos tem contestado, "fórmulas de governança estabelecidas, assim como suas hierarquias de posição e privilégio" (Holston, 2011, p. 335, tradução nossa), incluindo categorizações culturais. Nesse contexto, as obras também sinalizam a "democratização da literatura" indicada por Dalcastagnè. Por outro lado, os dois livros aqui discutidos, ao denunciarem múltiplos abusos de direitos humanos, revelam as insuficiências - as disjunções - da democracia brasileira após a transição de 1985 e que prevalecem até os dias de hoje.

Seguindo a cronologia da publicação dos dois textos, mas também considerando o desenvolvimento temático dos livros, que aponta para uma maior agência dos personagens, ou seja, sua maior inclusão na polis, primeiramente, será examinado o romance Graduado em marginalidade, para depois se discutir a biografia do autor, Como a água do rio. A progressão da agência dos personagens dos dois livros pode ser interpretada como um paralelo da consolidação democrática no campo civil, social e cultural no Brasil. 


\section{Graduado em marginalidade}

Escrito em 2004 e inicialmente publicado em 2005 pela Editora Scortecci, 7 Graduado em marginalidade é o primeiro romance de Sacolinha. Ainda que tenha sido composto já durante o primeiro governo Lula (2003-2007), durante o qual medidas sociais, como o Bolsa Família, ajudaram a tirar milhões de brasileiros da pobreza extrema, diminuindo a desigualdade social, Graduado em marginalidade aponta a persistência de injustiça social no país apesar desses avanços socioeconômicos.

O final do romance assinala a transformação da realidade socioeconômica no país. A voz narrativa descreve medidas sociais que ajudaram na ascensão da classe C: "O ano 2001 chegou. As pessoas que nem sequer sonhavam em ter telefones em suas residências foram beneficiadas pelo governo. [...] As casas de aluguel aos poucos são trocadas por casa próprias. Devido aos variados tipos de financiamentos e empréstimos, os carros estão tomando os lugares das bicicletas na periferia" (Sacolinha, 2005, p. 157). A transformação do espaço periférico por meio do consumo não significa, no entanto, o fim das práticas de violência decorrentes da desigualdade não apenas social mas também civil. Se, por um lado, programas como o Bolsa Família puderam diminuir o número de pessoas vivendo em condições de pobreza extrema - ou seja, com menos de R $\$ 71,75$ ao mês $-{ }^{8}$ por outro lado, o Brasil continua sendo um dos países mais desiguais do mundo. ${ }^{9}$

A desigualdade social implica também uma desigualdade no plano político e civil, assim como práticas discriminatórias na esfera social e cultural. Graduado em marginalidade focaliza essa realidade. O romance justapõe os avanços materiais, como a aquisição de celulares ou de casa própria, com a continuidade da desigualdade socioeconômica e a violência cotidiana enfrentada pelos residentes da periferia. O livro

\footnotetext{
${ }^{7} \mathrm{O}$ romance teve uma reedição em 2009 pela Confraria do Vento.

8 Conforme relatório do Banco Mundial (2015, p. 81, fig. 3.1), entre 2001 e 2013, a pobreza extrema caiu de $9,9 \%$ para $4 \%$ no Brasil.

${ }^{9}$ Conforme reportagem de Alvarenga (2015), referindo-se a dados de 2013 publicados pela Receita Federal, " $1 \%$ dos contribuintes concentram (em 2013) cerca de $30 \%$ de toda riqueza declarada em bens e ativos financeiros." E um pequeno número de 71 mil brasileiros $(0,3 \%$ dos declarantes de IR) concentrava, naquele ano, $14 \%$ da renda nacional e $22 \%$ da riqueza.
} 
demonstra como a injustiça social transforma os moradores da periferia em pseudocidadãos. ${ }^{10}$

Graduado em marginalidade aborda temas como a deficiência do sistema público de saúde, a violência em comunidades de baixa renda, a corrupção e brutalidade policial, a injustiça do sistema judiciário/penal brasileiro, entre outros, expondo a realidade de uma democracia disjuntiva na qual a discriminação continua a perdurar no campo social e civil, apesar da democratização no campo político. O romance de Sacolinha se concentra, assim, na representação dos direitos negativos, ou seja, na necessidade de proteção contra abusos sociais, políticos ou civis. Esse enfoque, indiretamente, também denuncia a falta de direitos positivos (agência) dos residentes das periferias urbanas brasileiras.

Graduado em marginalidade narra a transformação de Vander/Burdão, um jovem residente da Vila Clementina, em Brás Cubas, distrito de Mogi das Cruzes (Grande São Paulo), de "rapaz comum" a líder do tráfico de drogas na sua comunidade. Órfão de pai e mãe, Vander se vê perseguido por um policial corrupto, Lúcio Tavares, que assume o controle do narcotráfico na Vila Clementina, corrompendo o outrora relativamente pacífico bairro. Tavares tenta também corromper Vander, incitando-o a participar de sua equipe de traficantes. Mas como Vander inicialmente se recusa a entrar para a vida do crime, o policial passa a persegui-lo.

Após vários abusos - incluindo tortura e prisão injusta -, Vander/Burdão decide abandonar sua integridade e entra para a criminalidade. Ele expulsa Lúcio e sua gangue de policiais corruptos da Vila Clementina e assume a liderança do tráfico de drogas na comunidade. Além do título do romance, a dualidade do nome do protagonista - que é usado aleatoriamente durante o livro - também sugere a metamorfose deste desde o começo da narrativa. Se de um lado tem-se Vander, o "rapaz comum", que gosta de ler e busca um emprego "honesto", por outro, encontra-se Burdão, que alude à transformação violenta (ainda que forçada) do personagem, sua formação através da violação de seus direitos humanos (assim como os direitos da comunidade em que o protagonista vive).

Os dois nomes do personagem principal simbolizam a tensão entre a cotidianidade, que no começo caracteriza a vida do protagonista -

\footnotetext{
${ }^{10}$ Janice Perlman (2008, p. 277, tradução nossa) sugere que: "os pobres não são cidadãos integrais enquanto tantos estiverem desempregados e desprotegidos da polícia e da violência do tráfico nas suas comunidades."
} 
destruída pela corrupção policial -, e a injustiça social que permeia o romance. Vander, que no início do livro é um jovem honesto e trabalhador, simbolicamente se gradua em marginalidade na "escola" do sistema penal/de segurança brasileiro: "o culpado disso tudo é um policial chamado Lúcio, que jogou ele no porão da sociedade sem nada dever. Foi por causa dele que foi torturado, passou fome, brigou, foi humilhado, matou, pegou em armas de fogo e se envolveu neste mundo que agora é difícil sair" (Sacolinha, 2005, p. 141). A modificação do personagem principal do romance - e seu final - implícitos na citação transmite uma mensagem ambígua. Por um lado, o texto propõe que o crime não compensa; por outro, sugere que a transgressão é uma das poucas formas de resistência que os moradores de comunidades periféricas têm diante de um sistema injusto e corrupto. Ou seja, trata-se de uma agência negativa. Holston argumenta que a ambivalência da democracia disjuntiva, em que se combina maior participação política com "violência, injustiça e impunidade" (Holston, 2008, p. 304, tradução nossa), faz com que a violência criminal apareça como uma resposta a essas condições sociais.

Graduado em marginalidade reproduz a mensagem de vários escritores periféricos que denunciam a violência e a criminalidade que são impostas de fora e que também são perpetuadas dentro da comunidade. ${ }^{11}$ Nesse sentido, o romance de Sacolinha assume um caráter de denúncia social. Os personagens de Graduado em marginalidade têm vários de seus direitos básicos infringidos, como proteção contra prisão arbitrária (art. 9 da Declaração Universal dos Direitos Humanos - DUDH, art. 54 da Constituição brasileira de 1988) e contra a tortura (art. 5 da DUDH e art. 43 da Constituição de 1988), além do direito à livre escolha do trabalho (art. 23 da Declaração Universal dos Direitos Humanos e art. 2 da Constituição de 1988), entre outros. Mais que isso, o romance sugere que a violação é incrementada pela falta de mecanismos de proteção contra esses abusos, como um sistema legal que persegue em vez de proteger os setores menos privilegiados - uma temática que se repetirá também em outro romance de Sacolinha, Estação Terminal (2010).

Estilisticamente, Graduado em marginalidade também assume o caráter de denúncia. A narrativa segue uma cronologia linear e a linguagem é simples

\footnotetext{
${ }^{11}$ Os exemplos mais conhecidos desse tipo de produção literária talvez sejam os dois primeiros romances de Ferréz, Capão pecado (que tem uma trama bastante semelhante à de Graduado em marginalidade) e Manual prático do ódio.
} 
e coloquial. No entanto, ao contrário de muitos outros escritos periféricos, incluindo o segundo romance de Sacolinha, o texto em geral não faz uso de gírias, abrindo mão, assim, do mecanismo de verossimilhança que tal linguajar sugere (não obstante, por seu turno, o estilo realista do romance, incluindo sua trama linear, promove a ideia de verossimilhança). A linguagem corriqueira, mas sem abundância de jargão, pode ser interpretada como uma forma de promover a identificação entre leitor e protagonista. Ao usar um linguajar mais padronizado, Sacolinha elimina até certo ponto a identificação grupal que gírias típicas de certas camadas sociais/espaços podem evocar, abrindo assim o horizonte de identificação entre leitor e protagonista/ação narrativa.

Como sugere a historiadora norte-americana Lynn Hunt (2007), a ideia dos direitos humanos pressupõe o conceito de um sujeito autônomo e com o qual podemos nos identificar. Graduado em marginalidade enfatiza a ideia de autonomia na negação de Vander em se submeter à autoridade de Tavares e se deixar corromper por este. Essa recusa também simboliza a rejeição do protagonista de se conformar aos estereótipos negativos associados aos sujeitos da periferia (nesse caso, o envolvimento com a criminalidade). Ou seja, Vander recusa se submeter ao sistema.

Em contraposição aos estereótipos negativos, a ética de Vander o transforma em um personagem com o qual o leitor quer/pode se identificar, apesar de um possível diferencial social entre os dois. O texto joga com essa ideia ao converter Vander em uma projeção do leitor. Como este, o personagem "Abria o livro e viajava nas histórias do tráfico, algumas das suas leituras já começavam com morte e pessoas fumando crack, e isso ele adorava, mas sempre ali na teoria" (Sacolinha, 2005, p. 140). A passagem estabelece uma distância entre Vander e o mundo de criminalidade que emula a distância entre o leitor e esta esfera. A aproximação de ambos se dá, pelo menos em um primeiro momento, através da leitura. No entanto, para o protagonista, essa distância é destruída pela arbitrariedade policial e a corrupção do sistema legal. Vander acaba se transformando em um dos personagens sobre os quais ele lia. Essa transformação textual de sujeito leitor a personagem de leitura imita sua progressiva perda de direitos positivos.

Além da trama, o caráter de denúncia do romance também é enfatizado por passagens alegóricas que sublinham tanto a injustiça social abordada na história quanto o desejo de recompor algum tipo de justiça social: “Depois que Vander foi torturado, não mais sentia o 
cheiro doce e suave que as flores ofereciam, não sorria e perdeu o amor pelas coisas" (Sacolinha, 2005, p. 118). A oração transmite a ideia do rompimento brutal de uma cotidianidade e de uma futuridade, simbolizado pelo "cheiro doce e suave" das flores. Por um lado, a constante negação de seus direitos desumaniza o protagonista; por outro, a violência que sofre faz com que Burdão procure meios de reagir à injustiça que percebe a seu redor.

Graduado em marginalidade abre-se com uma dedicatória e uma epígrafe. A dedicatória traça a genealogia matrilinear de Ademiro Alves, começando com Isabel Alves de Sousa, que dá início às Alves através de sua união com um senhor de escravos. Já a epígrafe é o poema "O alquimista", de Sérgio Vaz, que de certo modo conclui a genealogia iniciada por Isabel Alves de Sousa: "Com o sentimento no cativeiro [...] Abusado feito artista/transformou chumbo em ouro/nunca usou anel de polícia/essa magia é o seu maior tesouro" (Sacolinha, 2008, p. 11). A prole gerada sob o signo da violência escravocrata transforma-se no sujeito periférico, sujeito que se equilibra na corda bamba entre a criatividade e a resistência violenta a um sistema que continua a operar de forma discriminatória. A continuidade da violência social também é sugerida pela circularidade do romance. A narrativa abre com um sonho em que Burdão está sendo justiçado por policiais e termina com a concretização do pesadelo.

A trajetória de Vander entre um pesadelo e outro começa no momento em que o pai do protagonista é assassinado em um assalto. O romance insinua que até ali o movimento era de ascensão ou pelo menos de estabilidade social, tanto para a família de Vander, como para sua comunidade. Assim, logo no início do livro, a voz narrativa descreve o processo de autoconstrução da comunidade em termos de edificação de casas e de infraestrutura, bem como da constituição de uma cidadania, que está ligada a essa autoconstrução. A voz narrativa do romance observa que "com o passar dos anos os moradores foram trocando os madeirites por blocos baianos. O prefeito de Mogi das Cruzes sabia que mais um bairro estava se formando, mas não deu importância alguma até que os moradores mais espertos do local resolveram se mexer" (Sacolinha, 2005, p. 17). Segundo Holston, os locais da autoconstrução, ou seja as periferias urbanas brasileiras, são também os lugares onde se constituem as manifestações da cidadania insurgente, que reclama a equalização dos direitos. Essa conjunção se dá justamente porque as condições de cidadania diferenciada que levam à 
autoconstrução nas periferias metropolitanas também são "as condições da sua subversão, com as quais os pobres urbanos ganham direitos políticos, se transformam em proprietários de terras, usam a lei em seu benefício, criam novas esferas públicas de participação, atingem o direito à cidade e se tornam consumidores modernos" (Holston, 2008, p. 9, tradução nossa). Holston afirma que, ao transformar o quadro urbano através da autoconstrução, do pagamento de impostos (consequência da legalização de comunidades informais) e do consumo, os residentes de áreas periféricas passam a se considerar como agentes de transformação da esfera urbana. Sua participação nesse processo, por sua vez, outorga direitos de contribuinte - reivindicações de direitos baseadas nas contribuições que esses residentes fazem à cidade na forma de serviços prestados, melhoria de infraestrutura, entre outros (Holston, 2011, p. 347). Ou seja, a autoconstrução não apenas promove os direitos sociais de sujeitos periféricos (propriedade, consumo) mas também seus direitos civis e, em certos casos, seus direitos políticos.

Em sua análise da relação entre direitos, cidadania e transformação urbana, Holston assinala a conjunção entre a propriedade privada e a agência dos residentes periféricos. Essa correlação é elaborada ao longo do romance de Sacolinha. Se, por um lado, a autoconstrução e a estabilidade material da família de Vander constituem um fator de cidadania, por outro, a perda dessa estabilidade erode os direitos de Vander. Não é de se surpreender que a anulação final dos direitos do protagonista é simbolizada pelo incêndio da casa do protagonista, causado pela vingança de Lúcio Tavares (Sacolinha, 2005, p. 118).

A destruição do lar coincide com a tortura de Vander, como punição depois de este ter espancado o assassino do pai na cadeia. Ao relatar a tortura de Vander, a narrativa destaca a vulnerabilidade e, paradoxalmente, a dignidade do protagonista. Vander sofre a dor, mas mantém sua integridade psíquica. ${ }^{12}$ A descrição da tortura física rompe com a ideia de integridade física que precede e acompanha a noção da dignidade do sujeito humano (Anker, 2013, p. 4). Mas essa quebra serve à construção do sujeito de direitos, já que "paradoxalmente, para serem legíveis, os conceitos simultâneos da dignidade humana e da integridade física requerem a ameaça de corpos sendo violados, quebrados e

12 "Os encapuzados estavam batendo e sorrindo, queriam ver sangue e ouvirem gritos, mas Burdão não dava esse gosto a eles” (Sacolinha, 2005, p. 115). 
profanados. Isto sugere que, ironicamente, o discurso e as normas dos direitos humanos são vinculados pelo seu oposto, por imagens de destruição e abuso físico" (Anker, 2013, p. 4, tradução nossa). A representação da tortura em Graduado em marginalidade afirma Vander como um sujeito de direitos. Consequentemente, a tortura e a destruição da propriedade privada justificam a virada do personagem para o crime.

Retornando à simetria entre indivíduo e comunidade à que o romance de Sacolinha alude, a história da família de Burdão corre paralela ao desenvolvimento da comunidade. A formação da família nuclear está baseada não só na estabilidade econômica simbolizada na figura paterna, mas também no respeito à instituição familiar. Jorjão, o pai de Vander, é descrito como "um grande pai, caminhoneiro, trabalhador, homem dedicado ao maior patrimônio do mundo que era a sua família" (Sacolinha, 2005, p. 17). A passagem enfatiza dois aspectos: a família e o trabalho. A descrição reforça a ideia de Jorjão como um sujeito de direitos. Para Holston, os residentes das periferias brasileiras se constroem como sujeitos de direitos a partir da ideia de "ser direito". Essa categoria implica que a pessoa em questão seja "um bom trabalhador, sustente sua família e seja uma pessoa honesta" (Holston, 2011, p. 344, tradução nossa). Em outras palavras, ter direitos está associado à noção de integridade moral e social. Além da autoconstrução e da representação de Jorjão como um membro produtivo da sociedade, a rotina dele, composta não apenas de trabalho mas também pelo lazer como uma forma de sociabilidade benéfica - a roda dominical de cerveja e samba nos bares da vizinhança -, serve para reforçar a ideia de probidade moral do personagem.

O quadro da normalidade e inteireza familiar construído a partir da figura de Jorjão indiretamente encontra seu paralelo na imagem do dia a dia na Vila Clementina. Apesar da presença do tráfico de drogas, a cotidianidade da comunidade é composta por cenas prosaicas como beatas fofoqueiras, jovens que jogam futebol ou saem à procura de emprego e crianças empinando pipas (Sacolinha, 2005, p. 35). Essa cotidianidade insinua que a maioria da população local é constituída por sujeitos parecidos com Jorjão, pessoas de caráter íntegro (como os jovens que procuram emprego). A caracterização de Jorjão é, de certa forma, metonímica da comunidade a que ele pertence.

Mesmo o tráfico de drogas na Vila Clementina é retratado como uma parte do cotidiano. A violência do crime organizado é compensada pelos serviços sociais que os narcotraficantes oferecem e que compensam a falta 
de assistência do Estado. Assim, por exemplo, o enterro de Jorjão é financiado por Escobar, o líder do tráfico na Vila Clementina. Esse retrato do tráfico ecoa a ideia de um Estado ausente e da função compensatória exercida pelo crime organizado nas comunidades periféricas. Holston afirma que a presença das quadrilhas do tráfico combina "execuções sumárias com fraldas, leite, medicamentos, combinando terror e serviços públicos" (Holston, 2009, p, 15, tradução nossa).

Considerando a noção de direitos associada à integridade moral, a morte violenta de Jorjão enfatiza a negação do direito a ter direitos. Sua morte não somente denuncia a violação do direito básico à vida, mas também revela a falha do sistema de segurança pública, assim como do sistema legal no âmbito individual e comunitário.

Para Joseph Slaughter, o discurso dos direitos humanos acopla o indivíduo e a comunidade que representa. Slaughter observa que o discurso legal dos direitos humanos considera o indivíduo como:

uma instância da identidade do grupo e a menor unidade da sociedade humana; assim sendo, o indivíduo também representa o ponto mais imediato e diferenciado da vulnerabilidade de um grupo às violações dos direitos humanos. De fato, muitos dos crimes cometidos contra o sujeito obviamente individualizado são violações da integridade do grupo, porque têm profundas consequências para a vitalidade do tecido social, assim como na constituição e participação na esfera pública (Slaughter, 2007, p. 160, tradução nossa).

Em Graduado em marginalidade, a crise desencadeada na unidade familiar pela morte violenta de Jorjão, metonimicamente, parece também iniciar uma série de outras catástrofes em nível comunitário, que arruínam tanto a sociabilidade da Vila Clementina como a/s família/s que dela fazem parte. Se antes da morte de Jorjão o espaço público era um espaço de sociabilidade e lazer (beatas fofocando, crianças brincando, rodas de amigos em torno de fogueiras noturnas, jovens jogando peladas), agora esse espaço é regido por uma lógica econômica, imposta por Lúcio Tavares (Sacolinha, 2005, p. 44-45). Os botecos da vizinhança exemplificam essa mudança. Se antes eram lugares de reuniões sociais, depois da invasão de Tavares, tornaram-se "inferninhos, lanchonetes da boca" (Sacolinha, 2005, p. 119). A modificação do espaço público, outrora terreno não só de sociabilidade, mas também de agência social e cívica (através do 
processo de autoconstrução) em um lugar de intercâmbio comercial (de mercadorias tanto legais como ilegais, incluindo o corpo humano) revela a atomização da Vila Clementina e o isolamento dos seus moradores, que, de potenciais portadores de direitos, transformam-se paulatinamente, em sujeitos da exclusão, sem direito a ter direitos.

Dessa forma, apesar do aceno a uma possível operosidade periférica no princípio do romance, Graduado em marginalidade enfoca mais os aspectos da diferenciação que os de uma insurgência produtiva. Além da criminalização dos jovens periféricos, o livro mostra as consequências da democracia disjuntiva, pelo tratamento que os moradores recebem de instituições do Estado, tais como o sistema de saúde pública ineficaz, o de educação fragilizado, a infraestrutura precária que caracterizam os bairros periféricos. Para Holston, a cidadania diferenciada implica que certos direitos só são disponíveis a determinadas camadas sociais. Holston observa que:

O funcionamento da cidadania diferenciada sempre incorporou altos índices de violência pública e privada, corrupção, abuso policial, impunidade, descrédito judicial, desrespeito à lei e privatização da justiça e segurança, além da violência estrutural da desnutrição, sistema de saúde disfuncional e todas as possibilidades de vida reduzidas pela pobreza generalizada (Holston, 2009, p. 20, tradução nossa).

Assim, por exemplo, o descaso no atendimento aos pacientes mais pobres acaba levando à morte de Dona Marina, mãe de Vander (Sacolinha, 2005, p. 62-63). Mas o que melhor exemplifica a cidadania diferenciada à que os moradores da periferia estão sujeitos no romance é a corrupção policial. Não somente não há possibilidade de acesso à justiça para os moradores, mas a corrupção da polícia é um agente de destruição de vidas e de comunidades periféricas. A polícia funciona como uma sinédoque de um Estado ausente ou abusivo.

Graduado em marginalidade insinua que o poder do Estado representado no romance por Lúcio Tavares -, em vez de promover os direitos dos moradores de bairros periféricos, muitas vezes elimina o poder de iniciativa e ação limitada que possuem, através de, entre outras coisas, sua marginalização. O romance ecoa, assim, o aumento do descrédito em relação às instituições judiciárias e policiais após a redemocratização (Holston, 2009, p. 13). 
Dentro de uma conjuntura de violência policial e de um judiciário ineficaz e preconceituoso, particularmente o jovem periférico, principalmente se este é afrodescendente, é transformado em um homo sacer $^{13}$ - o sujeito que pode ser morto sem punição. De acordo com Douglas Belchior (2015), em texto publicado em seu blog na Carta Capital, no qual faz referência a dados do Mapa da Violência no Brasil 2014, há aproximadamente 30 mil assassinatos de jovens por ano no Brasil. Destes, quase $80 \%$ são de jovens negros. Ainda de acordo com Belchior, de acordo com os dados do índice de vulnerabilidade juvenil à violência e desigualdade (IVJ) de 2014, no Brasil, entre 2002 e 2012, o número de mortes por homicídio de jovens brancos diminuiu $32,3 \%$, enquanto o de jovens negros aumentou $32,4 \%$. As causas desses números são várias, entre elas a violência policial. Ainda, citando dados da Human Rights Watch (HRW), Belchior informa que a morte de jovens negros por "auto de resistência" aumentou quase $100 \%$ na capital paulista em 2014 em relação a 2013. Muitas dessas mortes apresentam indícios de que as vítimas foram executadas ("com tiros na nuca, cabeça ou costas a curta distância").

Emblemáticos da criminalização do jovem da periferia são os amigos de Vander. Se, no início do romance, estes demonstram interesses e realizam atividades próprias à sua idade (namorar, jogar bola, ir a festas), pouco a pouco, vão sendo corrompidos pelo uso das drogas. $\mathrm{O}$ romance indica que não se trata propriamente de uma escolha e sim, pelo menos parcialmente, de uma imposição indireta de Lúcio Tavares, que vê na Vila Clementina o ponto de partida para "dominar todas as redes de tráfico do Alto Tietê, ser o distribuidor central de toda a desgraça alheia" (Sacolinha, 2005, p. 81). Para alcançar seus fins, Tavares não somente recruta os jovens da comunidade para o tráfico, mas também disponibiliza drogas para o seu consumo. Sua tática acarreta uma dupla exclusão dos jovens: não somente os transforma em membros da economia criminal, mas também os converte em objetos dessa economia.

A metamorfose dos amigos de Vander, de rapazes "comuns" a consumidores de drogas e, em seguida, a sujeitos da exclusão, sugere um sistema que suscita as causas da exclusão de sujeitos periféricos através de, entre outros, sua criminalização. Graduado em marginalidade

\footnotetext{
${ }^{13}$ Aludo aqui à definição dada pelo filósofo italiano Giorgio Agamben (1998), segundo o qual homo sacer é aquele que, excluído da polis, não pode ser sacrificado (ou seja, que não possui a capacidade de servir à sua comunidade através de sua morte), mas pode ser morto sem que sua morte seja castigada.
} 
critica não somente o sistema que gera esses mecanismos de exclusão (que, por sua vez, servem para justificar os abusos de direitos humanos cometidos pelos representantes da sociedade hegemônica contra sujeitos socialmente marginalizados), mas também aqueles que não resistem a esses mecanismos.

Seguindo um discurso que transparece em muitos textos da literatura periférica, Graduado em marginalidade sugere que as drogas vitimam o morador da periferia de várias formas. $\mathrm{O}$ consumo de entorpecentes torna os jovens mais vulneráveis a outras formas de abusos, incluindo o justiçamento. O fim trágico dos amigos de Vander, assim como deste, sugere esse ciclo vicioso. Graduado em marginalidade insinua que sair desse ciclo é quase uma impossibilidade. As tentativas de Vander - o trabalho honesto, a leitura -, em última instância, não o protegem de um sistema social que promove a violação dos direitos humanos dos sujeitos periféricos.

Graduado em marginalidade aborda a temática dos direitos humanos através da representação de sua ausência. Dentro dessa ausência se insere a insurgência violenta de Vander como forma de reivindicar não somente os direitos do indivíduo mas também da comunidade. Em sua análise da apropriação do discurso dos direitos humanos por gangues criminais, James Holston afirma que ao combinar a racionalidade da criminalidade com a dos direitos humanos, essas facções revelam de forma extrema tanto "os ganhos como as contradições dos movimentos de uma cidadania insurgente democrática" (Holston, 2009, p. 27, tradução nossa). O romance de Sacolinha sinaliza a continuidade da diferenciação dos direitos humanos que caracterizam a democracia disjuntiva. Dentro dessa configuração contraditória, Graduado em marginalidade indica que a violência transforma-se não somente em agente de exclusão, mas também em nova forma desta.

Em contraste à violência, o texto de Sacolinha aponta outras formas de obtenção de direitos. Entre estas, a que mais se destaca é a literatura. A leitura é uma parte integral do processo de formação e de conscientização do protagonista. Assim, por exemplo, Vander se conscientiza dos seus direitos através de leituras sobre a revolução cubana, Lawrence da Arábia, Marighella e Che Guevara, entre outros (Sacolinha, 2005, p. 117). Essas leituras, acopladas aos abusos permanentes que sofre, o motivam à insurgência. Como o próprio Sacolinha, Burdão descobre na leitura uma forma de agência. 
A literatura é também um espaço alternativo à violência que rodeia Vander. A literatura é contrastada com a realidade violenta que circunda o protagonista e que vitima muitos de seus amigos. Em uma cena a narrativa justapõe a leitura de Burdão com o consumo de drogas de um de seus conhecidos, Casquinha:

Enquanto Burdão viaja na literatura de José Louzeiro, Casquinha estica vinte centímetros de cocaína. O livro "Lúcio Flávio - o passageiro da Agonia" empolga a leitura de Vander, enquanto o nóia está feliz pelo que irá consumir. [...] Burdão para para refletir o penúltimo parágrafo, Casquinha começa a inspirar a carreira, antes de chegar ao fim, cai no chão, a veia que manda sangue para seu cérebro para de funcionar, [...] o seu coração finaliza os movimentos. Vander fecha o livro e vai dormir (Sacolinha, 2005, p. 151).

O contraste entre os dois personagens enfatiza o potencial da literatura de "salvar" o indivíduo através da conscientização. No entanto, Graduado em marginalidade não descreve a materialização da literatura em instrumento dos direitos humanos. Vander se conscientiza, mas não consegue transformar esta conscientização em direitos positivos, ou seja, implementá-los. No romance, a leitura é um refúgio e não uma saída. Diferentemente desse romance, a simbiose dos dois se dá em Como a água do rio. Aqui a literatura se transforma em sinônimo dos direitos humanos e se contrapõe aos mecanismos da democracia disjuntiva.

\section{Como a água do rio}

Se Graduado em marginalidade é uma espécie de exposé pessimista da realidade de comunidades periféricas brasileiras, centrando-se no retrato dos impactos da cidadania diferenciada, Como a água do rio opta pelo circuito oposto. Ao contrário do romance, Como a água do rio centraliza os direitos positivos dos sujeitos periféricos. Esses direitos são adquiridos através da atividade cultural, mais especificamente a produção e recepção literária. O autor propõe que a leitura emancipa as pessoas (Sacolinha, 2012, p. 190).

O livro, publicado na série Tramas Urbanas, é uma biografia de Sacolinha construída a partir de sua inserção no campo literário. Como a água do rio narra de que forma, depois de ter-se tornado leitor voraz, Ademiro Alves se transforma em escritor e ativista cultural (não necessariamente nesta ordem). Há uma conjunção entre a narrativa 
biográfica e o desenvolvimento da persona literária. O texto, narrado em primeira pessoa, segue uma cronologia linear que começa com o nascimento do autor: "Meu nome é Ademiro Alves de Sousa. Nasci às sete e meia da manhã, do dia 9 de agosto de 1983, na Casa de Saúde Dom Pedro II, em São Paulo" (Sacolinha, 2012, p. 12). A frase afirma o protagonismo do autor em sua própria história. Ao mesmo tempo, a abertura do livro indica que se trata de uma narrativa de vida, uma narração pessoal que se refere a um "passado que precisa ser compartido e um futuro que tem de ser construído coletivamente" (Schaffer e Smith, 2004, p. 8, tradução nossa). Sacolinha usa a narrativa de sua vida, começando por sua infância, para propor um futuro coletivo no qual a leitura seja um instrumento de cidadania.

Em seu livro sobre a relação entre direitos humanos e narrativas biográficas ("life narratives"), Kay Schaffer e Sidonie Smith estabelecem um paralelo entre a proeminência do discurso dos direitos humanos e a proliferação das narrativas biográficas. ${ }^{14}$ Para as autoras, narrativas biográficas proveem um terreno comum entre pessoas, culturas e experiências diversas, criando, assim, um espaço empático que pode gerar/fortalecer demandas por justiça social (Schaffer e Smith, 2004, p. 1). Como sugerem Schaffer e Smith, a compilação de histórias individuais sobre a violação e a reivindicação dos direitos humanos aponta para uma narrativa coletiva. Esta, por sua vez, pode suscitar interesse em outros relatos individuais sobre os direitos humanos (Schaffer e Smith, 2004, p. 3). Se Graduado em marginalidade evoca a conjunção entre indivíduo e comunidade para realçar a ausência de direitos, Como a água do rio propõe essa confluência como uma forma de demandar direitos positivos. A ideia de uma comunidade de direitos que se forma a partir da leitura é reforçada pela inclusão de depoimentos, notícias, poemas de várias pessoas que participaram da formação do autor e de seus projetos literários. Com isso, Graduado em marginalidade se transforma, até certo ponto, em um testemunho coletivo.

A ideia de comunidade é central em Como a água do rio. Como indicado por Érica Peçanha do Nascimento, em sua extensa pesquisa sobre a literatura periférica, esse gênero literário assume uma função representativa. Muitos textos tematizam a opressão e a violência das quais as comunidades periféricas são vítimas. Peçanha observa que há

\footnotetext{
${ }^{14}$ As autoras localizam essa confluência temporalmente na década de 1990.
} 
uma confluência entre a experiência individual dos autores e a experiência da coletividade da qual fazem parte. Dessa forma, a "origem social comum e as elaborações compartilhadas de 'marginalidade' e 'periferia' impulsionam os escritores a assumir o papel de porta-vozes dos sujeitos e espaços marginais na literatura e a conferir às suas obras uma significação estética e também política" (Peçanha, 2009, p. 87).

Como a água do rio é acompanhado por várias fotos, que ilustram os diferentes marcos da vida do autor e seus laços com sua comunidade, seja sua família, seja seus colegas e seu público em seus diferentes projetos culturais. Retratos de sua infância e de sua vida são acompanhados por imagens de eventos da Associação Cultural Literatura no Brasil, a organização cultural criada por Sacolinha em 2005. ${ }^{15}$ O livro também inclui fotos de várias outras atividades culturais em que o autor está/esteve engajado e de pessoas que o acompanham/acompanharam nesses projetos. As fotos, assim como o texto, relatam a trajetória de reivindicação de direitos culturais, sociais e civis do autor e de sua comunidade.

No livro de Sacolinha, a narrativa em primeira pessoa, reforçada pelas imagens que ilustram o desenvolvimento da voz narrativa, transmite a ideia do sujeito autônomo (Hunt, 2007), que luta por seus direitos e pelos direitos de sua comunidade ao mesmo tempo que estabelece um espaço de empatia entre sujeito da narrativa e leitor. Por um lado, as imagens do autor, de sua família e de suas atividades socioculturais concedem uma dimensão afetiva ao relato. ${ }^{16}$ Por outro, as fotografias também conferem materialidade à história.

Como mencionado anteriormente, diferentemente de Graduado em marginalidade, que se concentra na falta de direitos de sujeitos periféricos, consequência da democracia disjuntiva, Como a água do rio foca na reivindicação dos direitos que se dá através da literatura. Segundo a voz narrativa testemunhal do livro: "Acredito no livro como agente transformador do ser humano. Hoje procuro mostrar a muitas pessoas o que um livro pode fazer pela vida de alguém. Eles salvaram a minha e continuam salvando. A literatura também salva. Este é o meu

\footnotetext{
${ }^{15}$ A Associação Cultural Literatura no Brasil deu sequência ao primeiro projeto do escritor, o Projeto Cultural Literatura do Brasil, fundado em 2002.

${ }^{16}$ Ver, por exemplo, as fotos da infância do autor e, entre elas, as imagens "Sacolinha, com 8 anos, junto aos seus tios Elias e Luciano" ou "O autor de camisa estampada, com 13 anos, na rua da casa da avó, em Itaquera - SP” (Sacolinha, 2012, p. 15).
} 
testemunho" (Sacolinha, 2012, p. 196). As palavras do autor ecoam a apresentação que acompanha os livros da série de que é parte - Tramas urbanas -, que afirma a capacidade de agentes periféricos de "encontrar soluções originais, criativas, sustentáveis e autônomas" (Petrobras, 2012, p. 5) aos dilemas enfrentados por essas comunidades. Comum a muitos dos textos da coleção - assim como aos dois livros analisados neste ensaio (sendo que Graduado em Marginalidade não foi publicado na coleção Tramas urbanas) é a dialética entre marginalização e iniciativas e ação social e cultural (ambos conectados).

Como a água do rio, lançado em 2012, reflete a crescente agência de sujeitos periféricos não só em termos materiais (a emergência da Classe C) mas também em termos simbólicos. Nesse contexto, a ideia de leitura, de textualidade, é fundamental. De acordo com James Holston, o conhecimento textual dos seus direitos (text-based knowledge) tem promovido a luta pelos direitos dos sujeitos periféricos e o desafiar das relações de poder que os desfavorecem (Holston, 2011, p. 348).

Em Como a água do rio, Sacolinha enfatiza como a leitura traduz-se em direitos. Assim, por exemplo, ele relata como seu envolvimento com a palavra escrita (nesse caso, sua carteira de trabalho) literalmente o salva do abuso policial. O autor conta como é abordado na rua por dois policiais militares. Os PMs pedem os seus documentos, mas o autor não está com seu RG. No entanto: "eu li e adquiri uma informação que me salvou do abuso daqueles PMs. E ainda tive coragem de encará-los e mostrar que não era qualquer um" (Sacolinha, 2012, p. 21). A leitura (da carteira de trabalho) confere ao autor o conhecimento dos seus direitos civis. Esse conhecimento, por sua vez, evita que ele seja vítima da violência policial.

Em outro episódio - que poderia constituir o final alternativo (e mais feliz) de Graduado em marginalidade, Sacolinha inclui o testemunho do escritor Mano Cákis. Segundo Cákis, sua trajetória, marcada pela criminalidade, muda a partir do momento em que lê o romance de Sacolinha: "Encontrei ali o que precisava: um direcionamento" (Sacolinha, 2012, p. 90). As palavras de Cákis sugerem não só a importância da escrita na cidadania mas também do agente cultural como mediador dessa cidadania. A narrativa dos direitos, ou de sua violação, transforma-se em resistência contra a cidadania diferenciada. Sacolinha propõe que a literatura transforma os sujeitos da exclusão em sujeitos de direitos culturais e sociais. Ele cita as histórias de vários residentes da periferia que, 
como ele, encontraram na leitura e na escrita uma forma de concretizar seus direitos. Assim, um exemplo é Elizabete Silva Costa (Dona Bete), que

vivia para cima e para baixo em hospitais e farmácias e era catadora de ferro velho. Não tinha perspectiva nenhuma [...]. Despois que se envolveu com a associação [Cultural Literatura no Brasil] e se transformou em leitora, são raras as vezes em que visita uma unidade básica de saúde. Voltou para a escola e concluiu o ensino médio. Nesse primeiro ano do ponto de cultura ela trabalhou no espaço como articuladora cultural, e com isso não precisou mais sair catando ferro velho por aí (Sacolinha, 2012, p. 190-91).

A mudança e o empoderamento de Dona Bete ocorre tanto no âmbito material (seu trabalho como articuladora cultural),quanto na esfera ontológica. Sua identidade se transforma a partir da leitura. Ela passa a se perceber não como um sujeito de exclusão ("não tinha perspectiva nenhuma"), mas como um sujeito de direitos, que se educa e participa da esfera pública - no caso, da associação cultural.

Mas a atividade literária transcende o âmbito individual. Além da transformação particular de Sacolinha, Mano Cákis, Dona Bete e outros que aparecem no livro, Como a água do rio relata a mudança que ocorre na comunidade. Assim, por exemplo, atividades literárias dirigidas pelo escritor (em sua função de coordenador literário) transformam o quadro urbano com a montagem de bibliotecas públicas, atividades culturais como saraus e publicação de autores locais (Sacolinha, 2012, p. 68). Essas iniciativas mudam a identidade da comunidade. Se antes a Suzano era caracterizada pela falta de infraestrutura e pelo vácuo cultural (Sacolinha, 2012, p. 47), depois da ação de Sacolinha, a cidade passa a ser "uma referência para a literatura do Alto Tietê" (Sacolinha, 2012, p. 71). A mudança do espaço urbano cria um terreno de expressão de sujeitos cuja voz muitas vezes é ignorada pela sociedade dominante. A modificação de Suzano por meio da performance cultural também abre espaços em que membros da comunidade podem aceder a outros direitos. Assim, por exemplo, através do Pavio Erótico, um sarau dedicado à poesia erótica, Sacolinha promoveu a educação sexual e a promoção da diversidade sexual (Sacolinha, 2012, p. 62-3).

Como a água do rio se concentra, em boa parte, nas instituições culturais fundadas ou coordenadas por Sacolinha, começando pelo Projeto Cultural Brasil (Sacolinha, 2012, p. 27) ou o projeto Uma Janela para o Mundo - 
Leitura nas Prisões (Sacolinha, 2012, p. 178). ${ }^{17}$ Este último tinha como objetivo a conscientização literária tanto de pessoas privadas de liberdade como de funcionários que trabalham em penitenciárias. No cerne dessas idealizações, estão dois objetivos: o fortalecimento da comunidade periférica e o de grupos socialmente excluídos, por meio da conscientização e da reivindicação da cidadania através da leitura.

No entanto, Como a água do rio justapõe a exploração do terreno literário e seu emprego como instrumento social a uma realidade onde ainda prevalece a cidadania diferenciada. Se, por um lado, a prática da leitura revela e combate ao preconceito do sistema policial, gera espaços menos opressivos na prisão e melhora o quadro urbano, por outro lado, o texto demonstra que a leitura que possibilita o acesso aos direitos ocorre em condições materiais muitas vezes adversas. Há, por vezes, um contraste entre o ato da leitura como ato de cidadania e a negação da cidadania que ocorre devido à privação socioeconômica. Em uma cena que poderia ter sido tirada de Graduado em marginalidade, Sacolinha descreve como, por causa da falta de eletricidade em sua casa, ele tinha que ler à luz de velas ou, depois das queixas de sua mãe, à luz de uma lanterna. Similarmente, Vander lê à luz de um "velho e pequeno abajur" (Sacolinha, 2001, p. 49) para não incomodar a mãe doente. As duas cenas expõem a precariedade material em que vivem muitos residentes periféricos.

Lidos conjuntamente - ou de forma contrastiva -, os dois textos de Sacolinha revelam uma transformação da consciência da cultura periférica, cujo arco vai da denúncia da cidadania diferenciada à expressão de uma agência social e cultural. No entanto, embora Como a água do rio se concentre na posição proativa do agente cultural - posição esta que reflete também os princípios que referenciam a coleção na qual o texto foi lançado -, o livro também mostra as fissuras dentro do sistema social e cultural brasileiro. Essas fissuras apresentam desde o retrato das condições sociais em que vivem Sacolinha e sua família, incluindo o desaparecimento do padrasto do autor, até a descrição da casa onde vivem após se mudarem para Suzano, casa que não tinha "nem janelas, nem portas, nem portão" (Sacolinha, 2012, p. 24). Aparecem aqui ecos da violação de direitos básicos como o direito à moradia, trabalhados em Graduado em marginalidade. Mas o paralelo que existe entre as duas

${ }^{17}$ Projeto lançado em 2010, em parceria com a Unesco e os ministérios da Justiça, da Educação, da Cultura e do Desenvolvimento Agrário. Mais informações disponíveis em: 〈http://goo.gl/eLndJN〉. 
narrativas bifurca-se nesse ponto. Se Vander opta (forçadamente) pelo crime, o autor revela que a literatura o salva desse destino (Sacolinha, 2012, p. 32). O potencial da literatura como instrumento de promoção e defesa de direitos apontado no romance concretiza-se na biografia.

No entanto, as fissuras se fazem também aparentes na rejeição de Sacolinha em relação à classificação de textos como os seus de "literatura marginal". Ele afirma que "o que eu escrevo é literatura e ponto" (Sacolinha, 2012, p. 44). A reivindicação da obra literária do autor está associada a um empenho maior, o de resgatar o que Sacolinha acredita ser a verdadeira expressão literária brasileira, produzida por autores que "falam de mim, da favela, da tiazinha que levanta cedo, do batuque do candomblé etc." (Sacolinha, 2012, p. 27). A reivindicação da escrita centrada no espaço e no indivíduo periférico insere estes naquilo que Tennina chama de "geografia afetiva" da periferia, ao mesmo tempo em que os inclui em uma cartografia cultural mais ampla.

Como sugere Regina Dalcastagnè, citando a Nancy Fraser, a literatura pode servir como instrumento de luta contra a injustiça social ao incorporar as vozes subalternas dentro do espaço hegemônico que é o âmbito literário. A existência de textos como o de Sacolinha reflete uma mudança não somente no âmbito cultural, mas também na esfera social, pois indica que, apesar das continuadas desigualdades, abriram-se espaços para a produção cultural de atores periféricos - que se movimentam (lentamente) da periferia geográfica ao centro cultural. Esta movimentação pode-se traduzir em mais direitos para sujeitos periféricos.

\section{Referências}

AGAMBEN, Giorgio (1998). Homo sacer. Tradução de Daniel Heller-Roazen. Stanford: Stanford University Press.

ANKER, Elizabeth S. (2013). Fictions of dignity: embodying human rights in world literature. Ithaca: Cornell University Press.

ALVARENGA, Darlan (2015). 71 mil brasileiros concentram $22 \%$ de toda riqueza; veja dados da Receita. G1, Rio de Janeiro, $1^{\circ}$ ago. Disponível em: <http://goo.gl/th5jhy>. Acesso em: 3 ago. 2015.

ARENDT, Hannah (1951/1966). The origins of totalitarianism. New York: Harcourt, Brace \& World. 
BANCO MUNDIAL (2015). Prosperidad compartida y fin de la pobreza en América Latina y el Caribe. Washington. Disponível em: <https://goo.gl/PmBw0f>. Acesso em: 8 ago. 2015.

BELCHIOR, Douglas (2015). O genocídio da população negra pelo Estado brasileiro é denunciado em audiência da OEA em Washington, nos EUA. Carta Capital, 20 mar. Blog do Negro Belchior. On-line. Disponível em: <http://goo.gl/93oYCk> Acesso em: 4 ago. 2015.

DALCASTAGNÈ, Regina (2008). Vozes nas sombras: representação e legitimidade na narrativa contemporânea. In: DALCASTAGNÈ. Regina. Ver e imaginar o outro: alteridade, desigualdade, violência na literatura brasileira contemporânea. Vinhedo: Horizonte, p. 78-107.

ECKERT, Julia (2011). Introduction: subjects of citizenship. Citizenship Studies, Philadelphia, v. 15, n. 3-4, p. 309-317.

ESLAVA, Fernando V. (2004). Literatura marginal: o assalto ao poder da escrita. Estudos de Literatura Brasileira Contemporânea, Brasília, n. 24, jul./dez., p. 35-51.

FERRÉZ (2003). Manual prático do ódio. Rio de Janeiro: Objetiva.

FERRÉZ (2005). Capão pecado. Rio de Janeiro: Objetiva.

HOLSTON, James (2007). Citizenship in disjunctive democracies. TUCHIN, Joseph S.; RUTHENBURG, Meg. Citizenship in Latin America. Boulder: Lynne Rienner, p. 75-94.

HOLSTON, James (2008). Insurgent citizenship: disjunctions of democracy and modernity in Brazil. Princeton: Princeton University Press.

HOLSTON, James (2009). Dangerous spaces of citizenship: gang talk, rights talk and rule of law in Brazil. Planning Theory, Thousand Oaks, v. 8, n. 1, p. 12-31.

HOLSTON, James (2011). Contesting Privilege with right: the transformation of differentiated citizenship in Brazil. Citizenship Studies, Philadelphia, v. 15, n. 3-4, p. 336-352.

HUNT, Lynn (2007). Inventing human rights: a history. New York: W.W. Norton \& Company.

IPEA - INSTITUTO DE PESQUISA ECONÔMICA APLICADA (2013). Duas décadas de desigualdade e pobreza no Brasil medidas pela PNAD/IBGE. Brasília. (Comunicados do Ipea, n. 159). Disponível em: <http://goo.gl/0XXviK>. Acesso em: 8 ago. 2015.

NAÇÕES UNIDAS (1948). Declaração Universal dos Direitos Humanos. Paris, 10 dez. 
NASCIMENTO, Erica Peçanha do (2009). Vozes marginais na literatura. Rio de Janeiro: Aeroplano.

PERLMAN, Janice (2008). Redemocratization viewed from below: urban poverty and politics in Rio de Janeiro, 1968-2005. In: KINGSTONE, Peter; POWER, Timothy J. (Ed.). Democratic Brazil revisited. Pittsburgh: University of Pittsburgh Press, p. 257-280.

PETROBRAS (2012). Apresentação. In: SACOLINHA. Como a água do rio. Rio de Janeiro: Aeroplano.

PIVETTA, Rejane (2011). Literatura marginal: questionamentos à teoria literária. Ipotesi, Juiz de Fora, v. 15, n. 2, p. 31-39, jul./dez.

SACOLINHA (2005). Graduado em marginalidade. São Paulo: Scortecci.

SACOLINHA (2012). Como a água do rio. Rio de Janeiro: Aeroplano.

SCHAFFER, Kay; SMITH, Sidonie (2004). Human rights and narrated lives: the ethics of recognition. New York: Palgrave Macmillan.

SLAUGHTER, Joseph R. (2007). Human rights, Inc: the world novel, narrative form, and international law. New York: Fordham University Press.

TENNINA, Lucía (2013). Saraus das periferias de São Paulo: poesia entre tragos, silêncios e aplausos. Estudos de Literatura Brasileira Contemporânea, Brasília, n. 42, p. 11-28.

Recebido em outubro de 2015.

Aprovado em fevereiro de 2016.

\section{resumo/abstract/resumen}

\section{Literatura e direitos humanos na obra de Sacolinha}

Leila Lehnen

Este artigo propõe examinar como textos de escritores da periferia urbana brasileira, especificamente a obra de Ademiro Alves, o Sacolinha, reivindicam os direitos humanos dos residentes da periferia, portanto de sua inclusão dentro da polis, através do nexo entre a representação da cotidianidade e da injustiça social na periferia urbana brasileira. Através da representação da injustiça social e do retrato da cotidianidade na periferia, que ocorrem de forma paralela nos textos aqui examinados, Sacolinha tanto aponta as condições socioeconômicas adversas em que vivem muitos residentes das periferias brasileiras, como valoriza a 
comunidade e a cultura da periferia. Seus textos sugerem que os moradores das periferias brasileiras não somente são vítimas de violações de direitos humanos, mas que também têm direito a ter direitos (Arendt, 1951).

Palavras-chave: Sacolinha, direitos humanos, injustiça social.

\section{Literature and human rights in Sacolinha's work}

\section{Leila Lehnen}

This article examines how literary texts written by authors from Brazil's urban peripheries, specifically the work of Ademiro Alves, also known as Sacolinha, claim the human rights of residents from the periphery. In so doing, these works also demand their inclusion into the polis. Peripheral literary texts voice these demands by depicting both daily life and social injustice in Brazil's urban peripheries. Through this joint portrayal, which occurs concurrently in the works this essay discusses, Sacolinha signals the adverse socioeconomic conditions in which many peripheral subjects live. At the same time, his representation also valorizes peripheral communities and cultural production. Sacolinha's texts thus suggest that residents of Brazil's urban peripheries are not only the victims of human rights violations, but also that they have right to have rights (Arendt 1951).

Keywords: Sacolinha, human rights, social injustice.

\section{Literatura y derechos humanos en la obra de Sacolinha}

\section{Leila Lehnen}

Este artículo examina cómo los textos de escritores de las periferias urbanas brasileñas, específicamente la obra de Ademiro Alves, o Sacolinha, reivindican los derechos humanos de los residentes de la periferia, y por consiguiente articulan su derecho de ser incluidos en la polis a través de la representación tanto de la vida cotidiana como de la injusticia social existente en la periferia urbana brasilera. A partir de la representación de estos planos, que ocurre de forma paralela en los textos aquí examinados, el autor revela las condiciones sociales adversas en las que viven muchos de los residentes de las periferias brasileñas, a la vez que articula una visión positiva de la comunidad y su cultura. Sus textos indican que los habitantes de las periferias no solamente son víctimas de violaciones de derechos humanos, sino que también tienen derechos a tener derechos (Arendt 1951).

Palabras clave: Sacolinha, derechos humanos, injusticia social. 